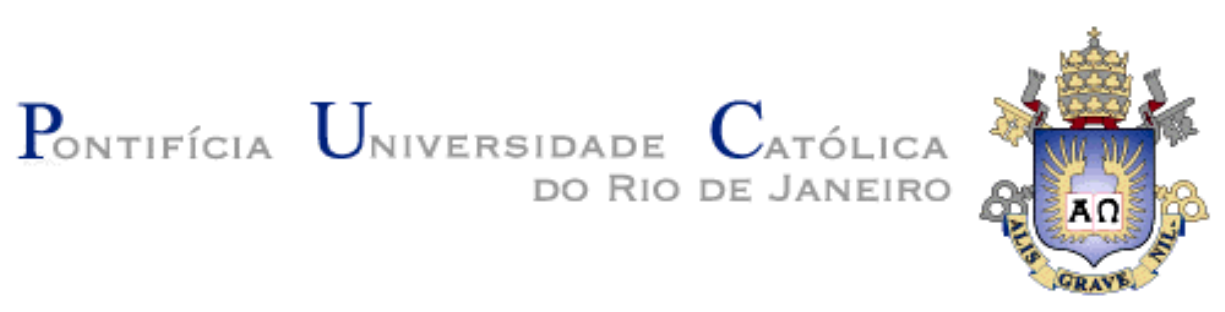

Leonardo Martins da Silva

\title{
Remoção de Cu e Co contido em soluções aquosas por Biossorção
}

\author{
Dissertação de Mestrado
}

Dissertação apresentada como requisito parcial para obtenção do título de Mestre pelo Programa de Pós-Graduação em Engenharia de Materiais e de Processos Químicos e Metalúrgicos do Departamento de Engenharia dos Materiais da PUC - Rio.

Orientador: Prof. Maurício Leonardo Torem

Rio de Janeiro

Agosto de 2010 


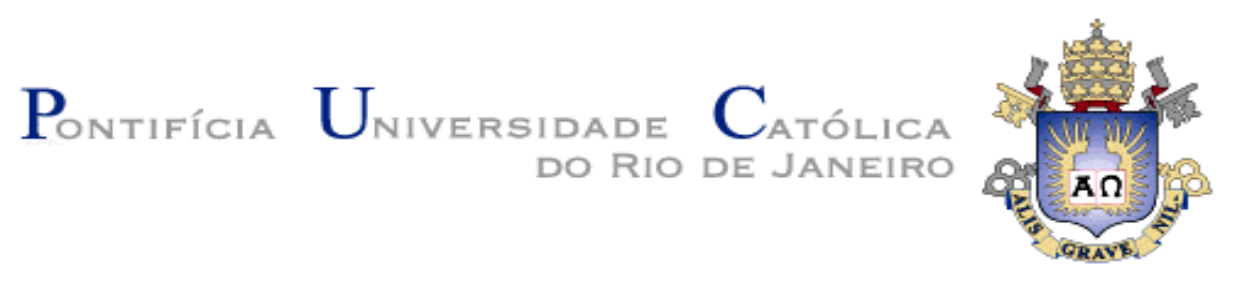

Leonardo Martins da Silva

\begin{abstract}
Remoção de Cu e Co contido em soluções aquosas por Biossorção
\end{abstract}

Dissertação apresentada como requisito parcial para obtenção do título de Mestre pelo Programa de Pós-Graduação em Engenharia de Materiais e de Processos Químicos e Metalúrgicos do Departamento de Engenharia de Materiais do Centro Técnico Científico da PUC-Rio. Aprovada pela Comissão Examinadora abaixo assinada.

\author{
Prof. Maurício Leonardo Torem \\ Orientador \\ Departamento de Engenharia de Materiais - PUC - Rio \\ Prof. Iranildes Daniel dos Santos \\ Departamento de Engenharia dos Materiais - PUC - Rio \\ Prof. Achilles Junqueira Bourdot Dutra \\ COPPE/ UFRJ - PEMM \\ Prof. Gabriela Huaman Pino \\ Departamento de Engenharia de Materiais - PUC - Rio \\ Prof. José Eugenio Leal \\ Coordenador (a) Setorial do Centro Técnico Científico - PUC - Rio
}

Rio de Janeiro, 25 de agosto de 2010. 
Todos os direitos reservados. É proibida a reprodução total ou parcial do trabalho sem autorização da universidade, do autor e do orientador.

\section{Leonardo Martins Da Silva}

Graduou-se em Química Industrial na Universidade Severino Sombra em Vassouras/RJ em 2006.

Ficha Catalográfica

Da Silva, Leonardo Martins.

Remoção de Co e Cu de solução aquosa por Biossorção e Bioflotação/Leonardo Martins da Silva; orientador: Maurício Leonardo Torem - Rio de Janeiro: PUC-Rio, Departamento de Engenharia dos Materiais, 2010.

132 f. : il. (color.) ; $30 \mathrm{~cm}$

Dissertação (Mestrado)-Pontifícia Universidade Católica do Rio de Janeiro, Departamento de Ciência dos Materiais e Metalurgia, 2010.

Incluí bibliografia.

1.Engenharia dos Materiais - Disertação. 2. Rhodococcus opacus. 3. Metais pesados. 4. Biossorção. $5 .$. I.Torem, Maurício Leonardo. III. Pontifícia Universidade Católica do Rio de Janeiro. Departamento de Engenharia dos Materiais IV. Título.

CDD: 620.11 
Em memória de meu pai, Anacleto da Silva. 


\section{Agradecimentos}

Ao orientador Professor: Maurício Leonardo Torem e a grande colaboradora Doutora Gabriela Huaman Pino pelo apoio e confiança depositados durante a realização deste trabalho.

A CAPES, ao CNPq e a PUC-Rio pelo auxílio financeiro concedido.

Aos técnicos, do laboratório de absorção atômica ICP/OES pelas análises realizadas.

Ao Professor Ulisses Casado Lins do Departamento de Ciências e Saúde CCS/UFRJ e a Dra. Karen Tavares.

Aos meus amigos, professores, pesquisadores e funcionários do Departamento de Engenharia dos Materiais da PUC-Rio, pelos ensinamentos e valiosas sugestões durante a realização deste trabalho. 


\section{Resumo}

Silva, Leonardo Martins; Torem, Maurício Leonardo. Avaliação da Remoção de Co e Cu de solução aquosa por Biossorção. Rio de Janeiro, 2010, 132p. Dissertação de Mestrado - Departamento de Engenharia de Materiais, Pontifícia Universidade Católica do Rio de Janeiro.

Neste trabalho, foi avaliada a capacidade de biossorção dos metais pesados, cobre e cobalto, utilizando como material biossorvente a biomassa bacteriana Rhodococcus opacus uma espécie microbiana de natureza não patogênica pertencente ao gênero Rhodococcus. Durante o processo de biossorção foram estudados vários parametros operacionais como: o pH da solução, a concentração de biomassa, o tempo de contato, e a concentração inicial do metal. O processo de avaliação feita em relação ao pH indicou uma melhor remoção no valor de pH 6 para o Cobre e valor de $\mathrm{pH} 7$ para o Cobalto. Com o pH estabelecido estudou-se as concentrações iniciais das espécies metálicas na faixa de 5 a 200 mg.L-1 Sendo obtido um melhor resultado com a concentração inicial 5 mg.L-1 para o metal cobalto e 15 mg.L-1 para o metal cobre. Logo em seguida foi avaliada a concentração inicial de biomassa numa faixa de 0,5 g.L-1 a 3,5 g.L-1 sendo a melhor porcentagem de remoção durante a concentração de biomassa de 3 g.L-1. Paralelamente foi avaliada a eficiência do processo de biossorção, após a realização de um pré-tratamento na biomassa com hidróxido de sódio $0,1 \mathrm{M}$. Os resultados foram mostrados em gráficos de porcentagem de remoção e captação. Os dados correspondentes à capacidade de captação do R. opacus em função da concentração dos íons metálicos foram bem ajustados ao modelo da isoterma de Langmuir obtendo-se um R2 de 0,9986 para o Co2+ e 0,9783 para o $\mathrm{Cu} 2+. \mathrm{Em}$ relação ao tempo de adsorção verificou-se uma rápida adsorção dada em 1 minuto de contacto da biomassa com íon metálico, na qual ajustou ao modelo cinético de pseudo segunda ordem. As características da superfície do micro-organismo e os possíveis mecanismos de interação envolvidos na biossorção dos metais pesados pela biomassa bacteriana R. opacus, foram avaliadas com base em medições de potencial zeta, análise por espectrometria no infravermelho e análise de 
micrografias obtidas no microscópio eletrônico de varredura (MEV).

\section{Palavras-chave}

Rhodococcus opacus; biossorção; cobalto; cobre. 


\section{Abstract}

Silva, Leonardo Martins; Torem, Maurício Leonardo (Advisor). Evaluation of the removal of co and cu from aqueous solution by biosorption. Rio de Janeiro, 2010, 132p. MSc Dissertation - Departamento de Engenharia de Materiais, Pontifícia Universidade Católica do Rio de Janeiro.

In this study, was evaluated the biosorption capacity of heavy metals, copper and cobalt, using a bacterial biomass Rhodococcus opacus as biosorbent microbial a species of non-pathogenic nature of the genus Rhodococcus. During the process of biosorption were avaliated various operating prametros as: $\mathrm{The} \mathrm{pH}$ of the solution, biomass concentration, contact time and initial metal concentration. The process of evaluation made in relation to the $\mathrm{pH}$ indicated a better removal at $\mathrm{pH} 6$ and $\mathrm{pH} 7$ for Coper and Cobalt. With the established $\mathrm{pH}$ were avaliated the initial concentrations of metal species in the range from 500 to 200 mg.L-1 after were evaluated the initial biomass concentration from 0.5 to 3.5g.L-1 being the best percentage of removal occurring in the biomass concentration of 3g.L-1. In parallel were evaluated the efficiency of the biosorption process after the completion of a pre-treatment with sodium hydroxide $0.1 \mathrm{M}$ The results were shown in graphs of percentage removal and uptake. The corresponding data to the uptake capacity of $\mathrm{R}$. opacus depending on the concentration of metal ions were well fitted to the model of the Langmuir isotherm to yield an R2 of 0.9986 and 0.9783 for metals copper and cobalt. Regarding the adsorption time there was a rapid adsorption in which we indicated a kinetic model of pseudo second order. The surface characteristics of microorganisms and the possible interaction mechanisms involved in heavy metal sorption by R.opacus were evaluated based on measurements of zeta potential, analysis by infrared spectrometry and analysis in a scanning electron microscope (SEM).

\section{Keywords}

Rhodococcus opacus; biosorption; cobalt; copper 
Sumário

1 Introdução

2 Objetivos e Relevância do Trabalho 22

2.1. Objetivo Geral 22

2.2. Objetivos Específicos $\quad 22$

3 Revisão Bibliográfica $\quad 24$

3.1. Cobre 24

3.1.1. Obtenção e utilização do Cobre 25

3.2. Cobalto 29

3.2.1. Obtenção e utilização do Cobalto 30

3.3. Efluentes contendo Cobalto e Cobre 32

3.4. Processos biotecnológicos 34

3.5. Técnicas de remoção de metais 36

3.5.1. Precipitação química 37

3.5.2. Flotação 39

3.5.3. Filtração por membrana 40

3.5.4. Troca iônica 43

3.5.5. Mecanismos de biossorção 45

3.6. Fatores que influenciam no processo de biossorção 48

3.6.1. $\mathrm{pH} \quad 49$

3.7. Concentração de biomassa 49

3.7.1. Temperatura 50

3.8. Estrutura bacteriana 51

3.9. Adsorção 52

3.9.1. Isotermas de adsorção 53

3.9.2. Isoterma de Freundlich 54

3.9.3. Isoterma de Langmuir $\quad 55$

3.10. Cinética da Sorção 56

$\begin{array}{ll}\text { 3.11. Potencial zeta } & 57\end{array}$ 
4 Materiais e Métodos $\quad 59$

4.1. Procedência e preparo da biomassa 59

4.2. Pré tratamento da biomassa 60

4.3. Experimentos de Biossorção em Batelada 60

4.4. Analise Quantitativa da Concentração dos Metais 61

4.5. Efeito do $\mathrm{pH} \quad 61$

4.5.1. Efeito da Concentração de Biomassa 62

4.5.2. Efeito da Concentração inicial de Metal 64

4.5.3. Determinação do Tempo de Equilíbrio 65

4.5.4. Efeito da temperatura no processo de biossorção 65

5 Resultados e Discussão 66

5.1. Estudos Electrocinéticos 66

5.2. Influência do $\mathrm{pH}$ nos processos de adsorção do íon $\mathrm{Cu}^{2+} \quad 68$

5.3. Influência do pH nos processos de adssorção do Cobalto 73

5.4. Efeito da Concentração inicial da Biomassa R opaccus no $\begin{array}{ll}\text { processo de biossorção } & 78\end{array}$

5.5. Efeito da concentração de íons metálicos no processo de biossorção 83

5.5.1. Cobre 83

5.5.2. Cobalto 86

5.5.3. Efeito da temperatura para a sorção dos metais 88

5.6. Perfil do tempo para a sorção dos metais 95

5.7. Isotermas de adsorção 100

5.7.1. Modelos de Isoterma de Adsorção 102

5.8. Caracterização do Material Biosorvente 111

5.8.1. Caracterização por Espectroscopia de Infravermelho 111

5.8.2. Caracterização por Microscopia eletrônica de Varredura 115

6 Conclusões e Recomendações para trabalhos futuros 120

6.1. Conclusões 120

6.2. Recomendações para trabalhos futuros 122 
7 Referências Bibliografica

Anexos

132

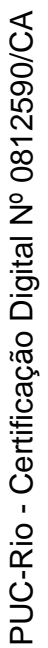




\section{Lista de figuras}

Figura 1 - Porcentagem do uso de cobre nos Estados Unidos. (Salaza, e McNutt, 2010).

Figura 2 - Porcentagem de exportação de Cobre realizado pelo

Brasil. (fonte: Anuário estatístico brasileiro, 2005).

Figura 3 - Porcentagem do uso de Co nos Estados Unidos. (Salaza e McNutt.,2010)

Figura 4 - Porcentagem de exportação de Co Realizado pelo Brasil em 2005. (Fonte: Anuário estatístico brasileiro, 2005)

Figura 5 - Mecanismo de adsorção bacteriana.

Figura 6 - Componentes da parede bacteriana gram positiva e gram negativa. (K. Vijayaraghavan e yeoung-sang yun.,2008)

Figura 7 - Estrutura da dupla camada elétrica. (adaptado Pino., 2007)

Figura 8 - Potencial Zeta das células $R$. opacus $\left(0.3 \mathrm{~g} \cdot \mathrm{L}^{-1}\right)$; influência do $\mathrm{pH}$ da solução em presença de metais (100 mg. $\left.\mathrm{L}^{-1}\right)$

Figura 9 - Diagrama de Predominância de $\mathrm{Cu}^{+2}$ em função do $\mathrm{pH}$ $\left(20 \mathrm{mg}^{\mathrm{L}} \mathrm{L}^{-1}\right)$,

Figura 10 - Diagrama de Especiação das espécies de $\mathrm{Cu}^{2+}$ presente numa concentração de $20 \mathrm{mg} \cdot \mathrm{L}^{-1}$ em função do $\mathrm{pH}$.

Figura 11 - Gráfico do $\mathrm{pH}$ de precipitação da espécie $\mathrm{Cu}^{2+}(20$ $\left.\mathrm{mg} \cdot \mathrm{L}^{-1}\right)$.

Figura 12 - Efeito do $\mathrm{pH}$ na biossorção de $\mathrm{Cu}^{2+}$ por $R$. opacus (concentração inicial de metal: $20 \mathrm{mg} \cdot \mathrm{L}^{-1}$; concentração de biomassa $1 \mathrm{~g} . \mathrm{L}^{-1}$; velocidade de agitação: $125 \mathrm{rpm}$; tempo de contato: $3 \mathrm{~h}$ ).

Figura 13 - Efeito do $\mathrm{pH}$ na biossorção de $\mathrm{Cu}^{2+}$ por $R$. opacus pré 
tratada com $\mathrm{NaOH}$ (concentração inicial de metal: 15 mg. $\mathrm{L}^{-1}$; concentração de biomassa $3 \mathrm{~g} \cdot \mathrm{L}^{-1}$; velocidade de agitação: 125 rpm; tempo de contato: 3 h). 72

Figura 14 - Predominância de $\mathrm{Co}^{2+}$ em função do pH $\left(20 \mathrm{mg}^{-\mathrm{L}^{-1}}\right), \quad 74$

Figura 15 - Diagrama de predominância Log $\mathrm{C}$ de Cu $\left(20 \mathrm{mg} \cdot \mathrm{L}^{-1}\right)$ em função do $\mathrm{pH}$.

Figura 16 - Gráfico do $\mathrm{pH}$ de precipitação do $\mathrm{Cu}^{2+}\left(20 \mathrm{mg}^{2} \mathrm{~L}^{-1}\right)$;

Figura 17 - Efeito do $\mathrm{pH}$ na biossorção de $\mathrm{Co}^{2+}$ pela biomassa $R$. Opacus (concentração inicial de metal: $20 \mathrm{mg}^{\mathrm{L}^{-1}}$; concentração de biomassa: $1,0 \mathrm{~g} \cdot \mathrm{L}^{-1}$; velocidade de agitação: 150 rpm; tempo de contato: 4h).

Figura 18 - Efeito do $\mathrm{pH}$ na biossorção de $\mathrm{Co}^{2+}$ pela biomassa $R$. Opacus pré tratada com $\mathrm{NaOH}$ (concentração inicial de metal: $20 \mathrm{mg} \cdot \mathrm{L}^{-1}$; concentração de biomassa: 1,0 g. $\mathrm{L}^{-1}$; velocidade de agitação: 150 rpm; tempo de contato: 4h).

Figura 19 - Efeito da Concentração de Biomassa R. opacus na biossorção de $\mathrm{Cu}^{2+}$ (concentração inicial de metal: 15 $\mathrm{mg} \cdot \mathrm{L}^{-1} ; \mathrm{pH}: 6,0$ velocidade de agitação: $125 \mathrm{rpm}$; tempo de contato: $3 \mathrm{~h}$ ).

Figura 20 - Efeito da Concentração de Biomassa na biossorção de $\mathrm{Cu}^{2+}$ pela biomassa $R$. opacus pré tratada com $\mathrm{NaOH}$ (concentração inicial de metal:15 mg. $\mathrm{L}^{-1} ; \mathrm{pH}: 6,0$ velocidade de agitação: 125 rpm; tempo de contato: 3 h).

Figura 21 - Efeito da Concentração de Biomassa $R$ opacus na biossorção de $\mathrm{Co}^{2+}$ (concentração inicial de metal: 15 mg. $\mathrm{L}^{-1} ; \mathrm{pH}: 7.0$ velocidade de agitação: $125 \mathrm{rpm}$; tempo de contato: 3 h).

Figura 22 - Efeito da Concentração de Biomassa na biossorção de $\mathrm{Co}^{2+}$ pela biomassa $R$. opacus pré tratada com $\mathrm{NaOH}$ (concentração inicial de metal: $5 \mathrm{mg} \cdot \mathrm{L}^{-1} ; \mathrm{pH}: 7,0$ velocidade de agitação: $125 \mathrm{rpm}$; tempo de contato: 
$3 h)$.

Figura 23 - Efeito da concentração do metal na biossorção do íon $\mathrm{Cu}^{2+}$ pela biomassa $R$. opacus (concentração de biomassa: 3 g. $\mathrm{L}^{-1}$; pH:6,0 velocidade de agitação: 125 rpm; tempo de contacto: $3 h$ ).

Figura 24 - Efeito da concentração do metal na biossorção do íon $\mathrm{Cu}^{2+}$ pela biomassa R.opacus (concentração de biomassa: 3 g. $\mathrm{L}^{-1} ; \mathrm{pH}: 6,0$ velocidade de agitação: 125 rpm; tempo de contacto: $3 \mathrm{~h}$ ).

Figura 25 - Efeito da concentração do metal na biossorção do íon $\mathrm{Co}^{2+}$ pela biomassa R.opacus (concentração de biomassa: $3 \mathrm{~g} . \mathrm{L}^{-1}$; pH:7,0 velocidade de agitação: 125 rpm; tempo de contacto: $3 \mathrm{~h}$ ).

Figura 26 - Efeito da concentração do metal na biossorção do íon $\mathrm{Co}^{2+}$ pela biomassa R.opacus pré tratada (concentração de biomassa: $3 \mathrm{~g} . \mathrm{L}^{-1} ; \mathrm{pH}: 7,0$ velocidade de agitação: 125 rpm; tempo de contacto: $3 \mathrm{~h}$ ).

Figura 27 - Efeito da temperatura na biossorção do íon $\mathrm{Co}^{2+}$ pela biomassa R.opacus (Temperatura $35^{\circ} \mathrm{C}$ concentração de biomassa: 3 g. $\mathrm{L}^{-1} ; \mathrm{pH}: 7,0$ velocidade de agitação: $125 \mathrm{rpm}$; tempo de contacto: $3 \mathrm{~h}$ ).

Figura 28 - Efeito da temperatura na biossorção do íon $\mathrm{Cu}^{2+}$ pela biomassa R.opacus (Temperatura $35^{\circ} \mathrm{C}$ concentração de biomassa: $3 \mathrm{~g} \cdot \mathrm{L}^{-1} ; \mathrm{pH}: 6,0$ velocidade de agitação: $125 \mathrm{rpm}$; tempo de contacto: $3 \mathrm{~h}$ ).

Figura 29 - Efeito da temperatura na biossorção do íon $\mathrm{Co}^{2+}$ pela biomassa R. opacus (Temperatura $45^{\circ} \mathrm{C}$ concentração de biomassa: 3 g.L-1; pH:7,0 velocidade de agitação: $125 \mathrm{rpm}$; tempo de contacto: $3 \mathrm{~h}$ ).

Figura 30 - Efeito da temperatura na biossorção do íon $\mathrm{Cu}^{2+}$ pela biomassa R.opacus (Temperatura $45^{\circ} \mathrm{C}$ concentração de biomassa: $3 \mathrm{~g} \cdot \mathrm{L}^{-1} ; \mathrm{pH}: 7,0$ velocidade de agitação: $125 \mathrm{rpm}$; tempo de contacto: $3 \mathrm{~h}$ ). 
Figura 31 - Efeito da temperatura na biossorção do íon $\mathrm{Cu}^{2+}$ pela biomassa R.opacus (Temperatura 45ำ concentração de biomassa: 3 g. $\mathrm{L}^{-1} ; \mathrm{pH}: 7,0$ velocidade de agitação: $125 \mathrm{rpm}$; tempo de contacto: $3 \mathrm{~h}$ ).

Figura 32 - Efeito da temperatura na biossorção do íon $\mathrm{Co}^{2+}$ pela biomassa R.opacus (Temperatura $45^{\circ} \mathrm{C}$ concentração de biomassa: 3 g. $\mathrm{L}^{-1} ; \mathrm{pH}: 7,0$ velocidade de agitação: $125 \mathrm{rpm}$; tempo de contacto: $3 \mathrm{~h}$ ).

Figura 33 - Efeito do tempo na biossorção do íon $\mathrm{Co}^{2+}$ pela biomassa R.opacus (Concentração de íon $15 \mathrm{mg} \cdot \mathrm{L}^{-1}$ concentração de biomassa: $3 \mathrm{~g} \cdot \mathrm{L}^{-1} ; \mathrm{pH}: 7,0$ velocidade de agitação: 125 rpm; ).

Figura 34 - Efeito do tempo na biossorção do íon $\mathrm{Cu}^{2+}$ pela biomassa R.opacus (Concentração de íon $15 \mathrm{mg} \cdot \mathrm{L}^{-1}$ concentração de biomassa: $3 \mathrm{~g} \cdot \mathrm{L}^{-1} ; \mathrm{pH}: 6,0$ velocidade de agitação: 125 rpm; ).

Figura 35 - O gráfico de pseudo primeira ordem linearizada para a biossorção de íons Cu2+ pela biomassa R.opacus (pH 6,0, concentração de biomassa: 3,0 g.L-1; taxa de agitação: 125 rpm ).

Figura 36 - O gráfico de pseudo primeira ordem linearizada para a biossorção de íons $\mathrm{Co}^{2+}$ pela biomassa R.opacus $(\mathrm{pH}$ 6,0, concentração de biomassa: $3,0 \mathrm{~g} \cdot \mathrm{L}^{-1}$; taxa de agitação: 125 rpm ).

Figura 37 - O gráfico de pseudo segunda ordem linearizada para a biossorção de $\mathrm{Cu}^{2+}$ íons na R.opacus ( $\mathrm{pH}$ 6,0, concentração de biomassa: $3,0 \mathrm{~g} \cdot \mathrm{L}^{-1}$; taxa de agitação: $125 \mathrm{rpm}$ ).

Figura 38 - O gráfico de pseudo segunda ordem linearizada para a biossorção de $\mathrm{Co}^{2+}$ íons na R.opacus (pH 7,0, concentração de biomassa: $3,0 \mathrm{~g} \cdot \mathrm{L}^{-1}$; taxa de agitação: $125 \mathrm{rpm}$ ).

Figura 39 - Efeito da Captação de Co2+ em função da variação 
da concentração de Co2+ por R.opacus (pH: 7.0 e 125 rpm; tempo de contato: $3 \mathrm{~h}$ ).

Figura 40 - Efeito da Captação de $\mathrm{Cu}^{2+}$ na variação da concentração de $\mathrm{Cu}^{2+}$ por R.opacus $(\mathrm{pH}: 6.0$; velocidade de agitação: $125 \mathrm{rpm}$; tempo de contato: 3 h).

Figura 41 - Gráfico da isoterma de Langmuir linearizada para a biossorção de $\mathrm{Co}^{2+}(\mathrm{pH} 7,0$, concentração de biomassa: 3,0 g.L.-1 taxa de agitação: $125 \mathrm{rpm}$ )

Figura 42 - Gráfico da isoterma de Langmuir linearizada para a biossorção de $\mathrm{Cu}^{2+}(\mathrm{pH}$ 6,0, concentração de biomassa: $3,0 \mathrm{~g} . \mathrm{L}^{-1}$ taxa de agitação: $125 \mathrm{rpm}$ )

Figura 43 - Gráfico da isoterma de Frendlich linearizada para a biossorção de $\mathrm{Co}^{2+}(\mathrm{pH}$ 7,0, concentração de biomassa: 3,0 g. $\mathrm{L}^{-1}$ taxa de agitação: $125 \mathrm{rpm}$ )

Figura 44 - Gráfico da isoterma de Frendlich linearizada para a biossorção de $\mathrm{Cu}^{2+}(\mathrm{pH}$ 6,0, concentração de biomassa: $3,0 \mathrm{~g} . \mathrm{L}^{-1}$ taxa de agitação: $125 \mathrm{rpm}$ )

Figura 45 - Espectro de infravermelho na concentração de 5 e 50 $\mathrm{mg} \cdot \mathrm{L}^{-1}$ para ambos os metais $\mathrm{Cu}^{2+} \mathrm{e} \mathrm{Co}^{2+}$

Figura 46 - Microfotografias do Microscópio Eletrônico de Varredura da biomassa in natura. $\mathrm{pH}$ do meio aquoso: 7; concentração de R. opacus: $3 \mathrm{~g} \cdot \mathrm{L}^{-1}$; tempo de contato de 3 h. Magnificação: 3300

Figura 47 - Composição elementar da biomassa in natura $\mathrm{pH}$ do meio aquoso: 7 , concentração de R. opacus : $3 \mathrm{~g} . \mathrm{L}^{-1}$, tempo de contato de 3h. Voltagem de aceleração: 20.0 kV Detector: NanoTrace.

Figura 48 - Microfotografias do Microscópio Eletrônico de Varredura da biomassa após adsorção de $\mathrm{Co}^{2+}$. ; concentração de $\mathrm{Co}^{2+} 5 \mathrm{ppm} ; \mathrm{pH}$ do meio aquoso 7 ; concentração de $R$. opacus foi $3 \mathrm{~g} \cdot \mathrm{L}^{-1} \mathrm{em}$ um tempo de contato de 3 h; Magnificação 3500 
Figura 49 - Composição elementar da biomassa após contacto com 5ppm de $\mathrm{Co}^{+2}$ em meio aquoso; $\mathrm{pH} 7$; concentração de R.opacus ; 3 g. $\mathrm{L}^{-1}$; Tempo de contato 3h; Voltagem de aceleração: 20.0 kV; Magnificação: 3500 ; Detector: NanoTrace

Figura 50 - Microfotografias do Microscópio Eletrônico de Varredura da biomassa após adsorção de $\mathrm{Cu}^{2+}$. Concentração 15ppm; $\mathrm{pH}$ do meio aquoso 6; Concentração de R.opacus $3 \mathrm{~g} . \mathrm{L}^{-1}$; tempo de contato de $3 \mathrm{~h}$.

Figura 51 - Composição elementar da biomassa após contacto com 15ppm de $\mathrm{Cu}^{2+}$ em meio aquoso. $\mathrm{pH}$ 6; concentração de $R$. opacus $3 \mathrm{~g} . \mathrm{L}^{-1}$; Tempo de contato foi de 3h; Voltagem de aceleração: 20.0 kV; Magnificação: 3500; Detector: NanoTrace. 


\section{Lista de tabelas}

Tabela 1 - Resoluções Normativas CONAMA 357/05 e 397/08. 24

Tabela 2 - Resumo das propriedades físico-química do cobre. 25

Tabela 3 - Principais companhias produtoras de cobre no Brasil. $\quad 27$

Tabela 4 - Estados brasileiros produtores de Cobre. 27

Tabela 5 - Produção mundial de cobre em toneladas. 28

Tabela 6 - Resumo das propriedades físicas do cobalto. 29

Tabela 7 - Produção mundial de cobalto em toneladas. 32

Tabela 8 - Principais poluentes de despejos industriais. 33

Tabela 9 - Características e diferenças entre métodos de bioacumulação e biossorção. 35

Tabela 10 - Diferenças dos métodos precipitação/coagulação/floculação e biossorção. 38

Tabela 11 - Diferenças entre métodos flotação e biossorção. 40

Tabela 12 - Diferenças entre métodos ultrafiltração e biossorção. 42

Tabela 13 - Diferença entre métodos osmose reversa e biossorção. $\quad 43$

,Tabela 14 - Diferença entre métodos troca iônica e biossorção. $\quad 45$

Tabela 15 - Grupos funcionais presentes na parede bacteriana. $\quad 48$

Tabela 16 - Condições empregadas para a determinação da influencia do pH no processo de biossorção. $\quad 61$

Tabela 17 - Condições empregadas para a determinação da influencia do $\mathrm{pH}$ no processo de biossorção (utilizando biomassa pré tratada com $\mathrm{NaOH}$ ). 62

Tabela 18 - Condições empregadas para a determinação da influencia da concentração de biomassa no processo de biossorção

Tabela 19 - Condições empregadas para a determinação da influencia da concentração de Biomassa (utilizando biomassa pré-tratada com $\mathrm{NaOH}$ ).

Tabela 20 - Condições empregadas para a determinação da 
influencia da concentração inicial de íon metálico no processo de biossorção.

Tabela 21 - Condições empregadas para a determinação da influência da concentração inicial de íon metálico no processo de biossorção (utilizando biomassa pré tratada com $\mathrm{NaOH}$ ).

Tabela 22 - Condições empregadas para a determinação da influencia da velocidade de captação no processo de biossorção.

Tabela 23 - Condições empregadas para a determinação da influencia da temperatura no processo de biossorção.

Tabela 24 - Variáveis empregadas nos modelos cinéticos pseudo primeira ordem para captação de $\mathrm{Co}^{2+} \mathrm{e} \mathrm{Cu}^{2+}$

Tabela 25 - Variáveis empregadas nos modelos cinéticos pseudo segunda ordem para captação de $\mathrm{Co}^{2+} \mathrm{e} \mathrm{Cu}^{2+}$.

Tabelas 26 - variáveis do modelo de captação de isoterma de

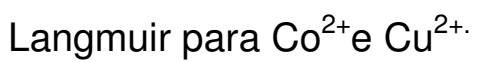

Tabela 27 - Variável do modelo de isoterma de Langmuir para captação do $\mathrm{Co}^{2+}$ em diferentes tipos de biomassas.

Tabela 28 - variável do modelo de isoterma de Langmuir para captação do $\mathrm{Cu}^{2+}$ em diferentes tipos de biomassas.

Tabela 29 - Variável do modelo de captação de isoterma de Freundlich para $\mathrm{Co}^{2+} \mathrm{e} \mathrm{Cu}^{2+}$

Tabela 30 - Variável do modelo de isoterma de Frendlich para captação do $\mathrm{Co}^{2+}$ em diferentes tipos de biomassas.

Tabela 31 - variável do modelo de isoterma de Langmuir para captação do $\mathrm{Cu}^{2+}$ em diferentes tipos de biomassas.

Tabela 32 - Grupos funcionais presentes na biomassa $R$. opacus após adsorção de $\mathrm{Co}^{2+}$.

Tabela 33 - grupos funcionais presentes na biomassa R.opacus in natura.

Tabela 34 - Grupos funcionais presentes na biomassa R.opacus após adsorção de $\mathrm{Cu}^{2+}$. 